Provided for non-commercial research and education use. Not for reproduction, distribution or commercial use.

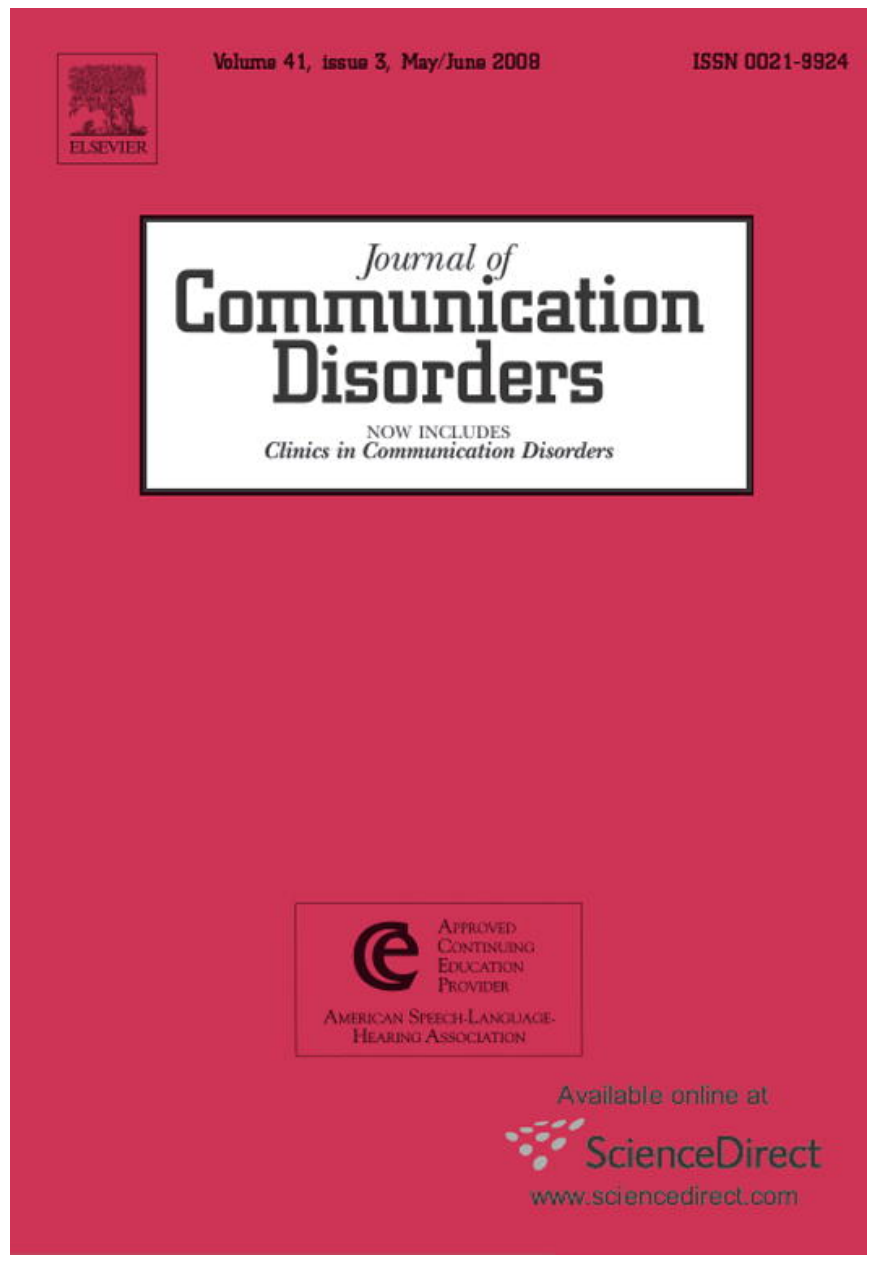

This article was published in an Elsevier journal. The attached copy

is furnished to the author for non-commercial research and education use, including for instruction at the author's institution, sharing with colleagues and providing to institution administration.

Other uses, including reproduction and distribution, or selling or licensing copies, or posting to personal, institutional or third party websites are prohibited.

In most cases authors are permitted to post their version of the article (e.g. in Word or Tex form) to their personal website or institutional repository. Authors requiring further information regarding Elsevier's archiving and manuscript policies are encouraged to visit: 


\title{
Consonants in Cri du chat syndrome: A case study
}

\author{
Kristian Emil Kristoffersen * \\ Department of Linguistics and Scandinavian Studies, University of Oslo, \\ P.O. Box 1102, Blindern, N-0317 Oslo, Norway
}

Received 23 April 2007; received in revised form 18 August 2007; accepted 31 August 2007

\begin{abstract}
This article reports on a longitudinal case study of consonant productions in one Norwegian girl with Cri du chat syndrome from age 4;6 to age 9;4. It was shown that she had many articulation errors throughout the period of observation. Furthermore, these errors were shown to fall into three main categories: (1) errors of differentiation and tuning, (2) errors of coordination and sequencing, and (3) missing gestures. Also, omissions of segments were reported to be frequent. In sum, the consonant productions by this girl were found to be both delayed and deviant, as compared to normally developing children. The number of errors, however, decreased as she grew older, resulting in more accurate renditions of the target words.
\end{abstract}

(C) 2007 Elsevier Inc. All rights reserved.

\section{Introduction}

This article examines the articulation of consonants in the speech of a Norwegian girl with Cri du chat (5p-) syndrome. Cri du chat syndrome (CCS) is a rare genetic disorder with an estimated incidence between 1:20,000 and 1:50,000 births (cf. Niebuhr, 1978; Wu et al., 2005) and is associated with a partial deletion on the short arm of chromosome 5. The clinical features of CCS include a high-pitched cry in infancy and childhood (Sparks \& Hutchinson, 1980; Sohner \& Mitchell, 1991), malocclusion, hyper- and hypo-tonia, delayed

\footnotetext{
* Tel.: +47 22857634; fax: +47 22857100 .

E-mail addresses: k.e.kristoffersen@iln.uio.no, k.e.kristoffersen@ilf.uio.no.
} 
motor development (Carlin, 1990), microcephaly (Niebuhr, 1978), mild-to-profound intellectual disability (Cornish, Bramble, Munir, \& Pigram, 1999), a short attention span, hyperactivity, and a stereotypical, aggressive, and self-injurious behaviour pattern (Collins \& Cornish, 2002).

Those affected with CCS experience delayed speech and language development (see Kristoffersen, submitted for publication, for an extensive literature review). According to the literature, a substantial share of individuals with CCS (reports vary from 23 to $50 \%$ ) do not develop spoken language at all (Carlin, 1990; Cornish \& Pigram, 1996; Baird et al., 2001; Wilkins et al., 1980). When those affected by CCS do develop spoken language, however, receptive language has been found to be significantly better than expressive language (Cornish \& Munir, 1998; Cornish et al., 1999).

In the domain of phonetics and phonology, which is the primary focus of the current article, the literature reports frequent misarticulations, such as omissions, substitutions, and distortions (Cornish et al., 1999; Schlegel et al., 1967; Sparks \& Hutchinson, 1980). Kristoffersen (2003b) identified and exemplified some types of misarticulations in the speech of one Norwegian girl with CCS, e.g., omissions (like [ $\mathfrak{H}]$ for $/ \mathrm{j} \mathrm{H}: \mathrm{s} /$ jus 'juice'), stopping (like [it] for /i:s/ is 'ice'), and cluster reductions (like ['patæ] for /'spa:də/spade).

Children with CCS have also been shown to have small consonant inventories, as compared to normally developing children. Kristoffersen (2003a, 2003b) conducted a longitudinal case study of his daughter Hanna, with particular focus on her development of consonant inventories, syllable structures, and phonological processes. Hanna's consonant inventories at three different ages $-4 ; 6,5 ; 9$ and 7;0 - are shown in Table 1 .

The target language in this case (i.e., urban east Norwegian, cf. Section 2) has 23 different consonant phonemes. Normally developing children learning Norwegian master the majority of these consonants by their third birthday, the exceptions being /s, r, 1, d, C, ç, j/ (cf. Kristoffersen, 2007, for a review of acquisition of consonants in normally developing Norwegian children). Thus, as Table 1 clearly shows, Hanna had far fewer consonants than normally developing Norwegian children. She also had some deviant consonants. First, there were plosives with nasal release at all three time points during the observation period, suggesting a problem with velopharyngeal function. Second, she had a linguolabial plosive at 5;9 and 7;0, indicating a lack of control of tongue movement. Finally, she reproduced both voiced and voiceless target plosives as voiceless plosives.

Table 1

Consonant inventories of one Norwegian girl with CCS (Kristoffersen, 2003a)

\begin{tabular}{|c|c|c|c|c|c|c|c|c|c|c|c|}
\hline \multicolumn{4}{|c|}{$4 ; 6$} & \multicolumn{4}{|c|}{$5 ; 9$} & \multicolumn{4}{|c|}{$7 ; 0$} \\
\hline $\mathrm{Lab}$ & Cor & Dor & Glo & $\mathrm{Lab}$ & Cor & Dor & Glo & $\mathrm{Lab}$ & Cor & Dor & Glo \\
\hline $\mathrm{p}$ & & $\mathrm{k}$ & & $\mathrm{p},\left(\mathrm{p}^{\mathrm{m}}\right)$ & $t, t\left(t^{n}\right)$ & $\mathrm{k}$ & & $p$ & $\mathrm{t}, \mathrm{t}$ & $\mathrm{k},\left(\mathrm{k}^{\mathrm{p}}\right)$ & \\
\hline $\mathrm{m}$ & $\mathrm{n}$ & $\eta$ & & $\mathrm{m}$ & $\mathrm{n}$ & $\eta$ & & $\mathrm{m}$ & $\mathrm{n}$ & $\mathrm{y}$ & \\
\hline (v) & 1, (1) & $\mathrm{j}$ & $\mathrm{h}$ & & 1 & $\mathrm{j}$ & $\mathrm{h}$ & (v) & $\begin{array}{l}\theta \\
1\end{array}$ & $\mathrm{j}$ & $\mathrm{h}$ \\
\hline & & & $?$ & & & & $?$ & & & & $?$ \\
\hline
\end{tabular}

The phonetic symbols in parentheses represent marginal phones, i.e., sounds, which occur only once or twice in the material (cf. Grunwell, 1985, 31). 
Table 2

Consonant inventories of three Norwegian children with CCS (Kristoffersen, 2004)

\begin{tabular}{|c|c|c|c|c|c|c|c|c|c|c|c|}
\hline \multicolumn{4}{|c|}{ Girl aged $10 ; 8$} & \multicolumn{4}{|c|}{ Boy aged $9 ; 2$} & \multicolumn{4}{|c|}{ Boy aged $10 ; 0$} \\
\hline $\mathrm{Lab}$ & Cor & Dor & Glo & $\mathrm{Lab}$ & Cor & Dor & Glo & Lab & Cor & Dor & Glo \\
\hline $\bar{p}, \mathrm{~b}, \widehat{\mathrm{mb}}$ & $\mathrm{t}, \mathrm{t}^{1}, \mathrm{~d}, \widetilde{\mathrm{nt}}$ & $c^{\prime}$ & & $\mathrm{p}, \overline{\mathrm{mb}}$ & $(\mathrm{t}), \widetilde{\mathrm{nd}}$ & $\mathrm{k}, \widehat{\mathrm{ng}}$ & & $\mathrm{p}$ & & & \\
\hline $\mathrm{m}$ & $\mathrm{n}$ & (n) & & $\mathrm{m}$ & (n) & $\mathrm{y}$ & & & & (y) & \\
\hline $\mathrm{f}$ & $\mathrm{s}, \underset{\theta}{\theta}$ & & $\mathrm{h}$ & (f) & & (ç) & & & $\theta$ & & $\mathrm{h}$ \\
\hline$v$ & 1 & $\mathrm{j}$ & & & & & & (w) & (1) & (j) & \\
\hline & & & & & & & $?$ & & & & $?$ \\
\hline
\end{tabular}

As can be seen in Table 2, these findings were corroborated by a study of the consonant inventories of three additional Norwegian children with CCS (Kristoffersen, 2004).

These previous studies point to concrete misarticulations and small consonant inventories. A shortcoming with the studies, however, is that they do not provide quantitative information about the different types of misarticulations, nor do they address the question as to whether the various errors decrease with increasing age or whether they persist.

The current study is an attempt to overcome this shortcoming by presenting quantitative data drawn from a longitudinal investigation of the articulation of consonants in one girl with CCS. This girl, Hanna, was the same girl who participated in the study reported by Kristoffersen (2003a, 2003b). She was followed for almost 5 years, from age 4;6 to age 9;4, and her consonants were examined with respect to two parameters, error rate and error patterns. Error rate was measured at four different ages, 4;6, 5;9, 7;0, and 9;4, in terms of percent consonants correct (PCC; Shriberg \& Kwiatkowski, 1982; Shriberg, Austin, Lewis, McSweeny, \& Wilson, 1997) and percent consonant clusters correct (PCCC; MacLeod, van Doorn, \& Reed, 2001; Smit, 1993). Furthermore, Hanna's articulation errors were classified according to a typology suggested by investigators working within the framework of articulatory phonology (Browman \& Goldstein, 1989; Studdert-Kennedy \& Goodell, 1995): missing gestures, errors of differentiation and tuning, and errors of coordination and sequencing.

It has been observed that children with disordered phonologies show a number of characteristics which are not found in normally developing children. Among these characteristics are persistence of error patterns, lack of progress, and unusual error types (Stoel-Gammon, 1991). This study, therefore, assessed Hanna's consonant productions with reference to these aspects, addressing the following specific questions:

- Did Hanna's error patterns persist throughout the period under investigation?

- To what extent was there progress in Hanna's production of consonants in the period under investigation?

- Did Hanna's speech display any unusual error types?

The article is organized as follows: Section 2 gives a brief outline of the relevant aspects of the Norwegian language, Section 3 outlines the methodology used in the study, Section 4 delineates the theoretical framework used in the analysis of error types, Section 5 presents the findings of the study, and Section 6 discusses them. 


\section{Urban east Norwegian: an outline of speech sounds and sound structure}

Norwegian belongs to the northern branch of the Germanic languages and is the major language spoken in Norway; 4,500,000 people use Norwegian as their first language. Hanna, the participant of this study, lives in Oslo, the capital of Norway. The regional variety of Norwegian spoken in this area is known as urban east Norwegian, henceforth referred to as UEN (cf. Kristoffersen, 2000).

\subsection{Phonemes}

UEN has 23 consonant phonemes and 18 vowel phonemes, cf. Tables 3 and 4 . There are two distinct sets of coronal consonants, one laminal (/t d n s l/) and one apical (/t, $\mathrm{d}, \mathrm{\eta}, \mathrm{S}, 1 /$ ). Furthermore, UEN differs from English in having voiceless fricatives only. The UEN $r$-sound is an apical tap. UEN also has an apico-postalvoeolar flap $/ \mathfrak{C} /$, which is also found in some dialects of Swedish, but not in the other Germanic languages. This consonant can occur wordmedially and -finally, but not word-initially.

\subsection{Phonotactic restrictions}

There are certain restrictions pertaining to the distribution of UEN consonants. First, the apical plosives $/ \mathrm{d} /$, the apical nasal $/ \mathrm{l} /$, the flap $/ \mathrm{r} /$, and the dorsal nasal $/ \mathrm{y} /$, cannot occur

Table 3

Consonant phonemes of urban east Norwegian

\begin{tabular}{|c|c|c|c|c|c|c|c|c|c|c|c|c|c|c|}
\hline \multicolumn{5}{|c|}{ Word-initial } & \multicolumn{5}{|c|}{ Word-medial } & \multicolumn{5}{|c|}{ Word-final } \\
\hline Lab & Ap & Lam & Do & Glo & Lab & Ap & Lam & Do & Glo & Lab & Ap & Lam & Do & Glo \\
\hline $\mathrm{p}$ & & $\mathrm{t}$ & $\mathrm{k}$ & & $\mathrm{p}$ & $\mathrm{t}$ & $\mathrm{t}$ & $\mathrm{k}$ & & $\mathrm{p}$ & $\mathrm{t}$ & $\mathrm{t}$ & $\mathrm{k}$ & \\
\hline $\mathrm{b}$ & & $\mathrm{d}$ & $g$ & & b & $\mathrm{d}$ & d & $g$ & & $\mathrm{~b}$ & $\mathrm{~d}$ & $\mathrm{~d}$ & $g$ & \\
\hline $\mathrm{m}$ & & $\mathrm{n}$ & & & $\mathrm{m}$ & $\eta$ & $\mathrm{n}$ & $\eta$ & & $\mathrm{m}$ & $\eta$ & $\mathrm{n}$ & $\eta$ & \\
\hline f & S & $\mathrm{S}$ & ç & $\mathrm{h}$ & f & S & $\mathrm{S}$ & ç & $\mathrm{h}$ & $\mathrm{f}$ & S & $\mathrm{S}$ & & \\
\hline$v$ & l & & $\mathrm{j}$ & & $v$ & $l$ & 1 & $\mathrm{j}$ & & $v$ & l & 1 & $\mathrm{j}$ & \\
\hline & ᄃ & & & & & r & & & & & r & & & \\
\hline & & & & & & r & & & & & r & & & \\
\hline
\end{tabular}

Table 4

Vowel phonemes of urban east Norwegian

\begin{tabular}{|c|c|c|}
\hline & Stressed syllables & Unstressed syllables \\
\hline Close & $\begin{array}{c}\text { i:, y: u:, u: } \\
\text { i, y, u, u }\end{array}$ & $\mathrm{i}, \mathrm{y}, \mathrm{u}, \mathrm{u}$ \\
\hline Mid & $\begin{array}{c}\text { e:, },, \text { o: } \\
\text { e, } \varnothing, \text { o }\end{array}$ & $\mathrm{e}, \varnothing, \partial, \mathrm{o}$ \\
\hline Open & $\begin{array}{l}æ:, \text { a: } \\
æ, \text { a }\end{array}$ & $æ, a$ \\
\hline
\end{tabular}


Table 5

Two element word-initial consonant clusters in UEN

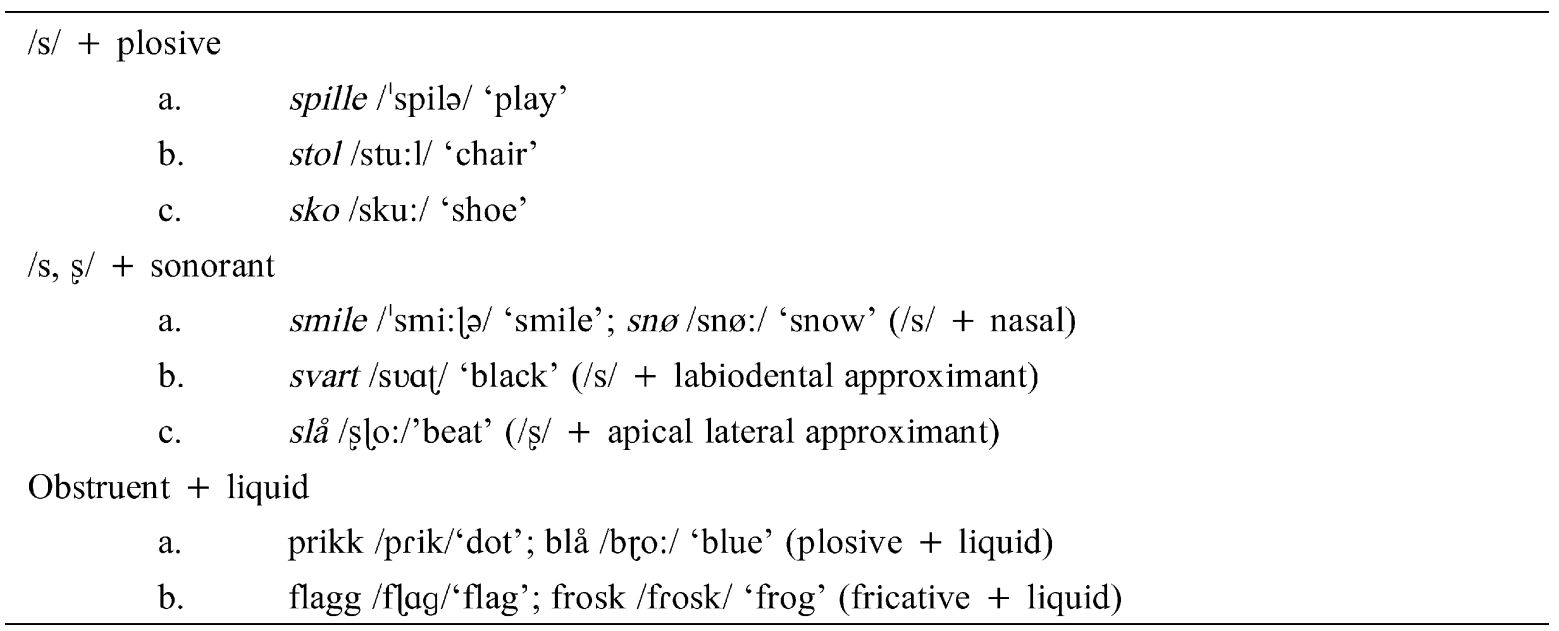

in the word-initial position. Second, the fricatives $/ \mathrm{h} /$ and /ç/ cannot occur in the word-final position. Third, the voiceless plosives have two allophones, an aspirated allophone, which occurs at the beginning of a stressed syllable and word-initially, and a non-aspirated allophone, which occurs in all other word positions.

\subsection{Consonant clusters}

UEN allows several different types of two-element consonant clusters in the word-initial position, cf. Table 5. First of all, clusters can consist of /s/ followed by a voiceless plosive. Second, they can consist of /s/ or /S/ followed by a sonorant. Finally, a word-initial twoelement cluster can consist of an obstruent followed by a liquid.

Also, some three-consonant clusters occur in UEN, the first member of which is always /s/ or (marginally) /S/, e.g. strå /stro:/ 'straw', skrive /'skri:və/ 'write', språk /spro:k/ 'language', and skli /skli:/‘skid'.

\section{Articulatory phonology}

\subsection{Articulatory gestures}

The theoretical framework used for describing the articulatory errors in Hanna's speech is articulatory phonology (AP). AP is a phonological model where the basic units of speech are taken to be actions, more specifically concrete movements by one or more articulators, e.g., lips, jaw, tongue tip, body of the tongue, velum, or glottis (Browman and Goldstein, 1989; Browman \& Goldstein, 1992; Byrd, 2003; StuddertKennedy \& Goldstein, 2003). The term gesture refers to an abstract unit of analysis which represents these concrete movements. Gestures belong to three different subsystems of the vocal tract, the laryngeal, the velic, and the oral subsystem, and can therefore be specified with respect to two sets of values, one designating constriction 


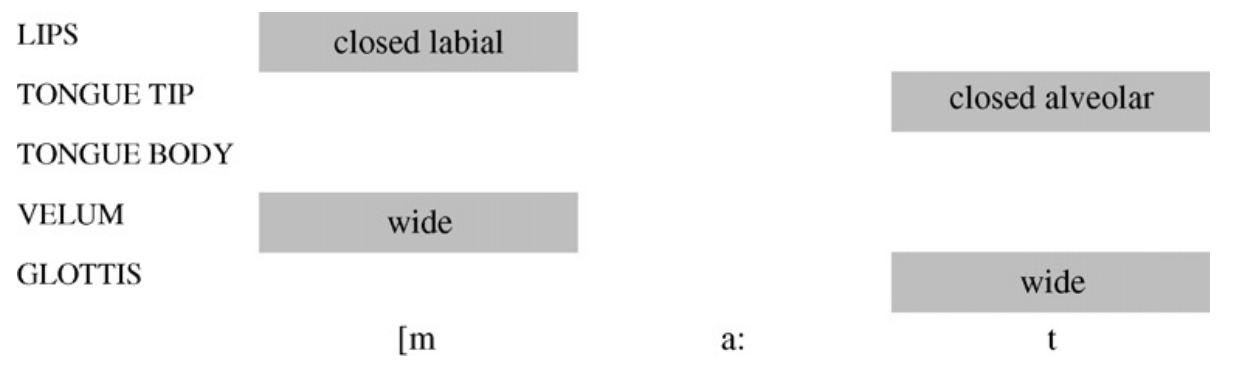

Fig. 1. Gestural score for mat 'food'.

location (CL) and one designating constriction degree (CD; Browman \& Goldstein, 1989, 209) ${ }^{1}$ :

- CL values: Protruded [lips], labial, dental, alveolar, post-alveolar, palatal, velar, uvular, and pharyngeal.

- CD values: Closed, critical, narrow, mid, and wide.

The terms closed and critical $^{2}$ correspond to the traditional terms stop and fricative, respectively, and the three terms narrow, mid, and wide cover three height degrees for vowels. All of the aforementioned CL and CD values are relevant to the oral subsystem. For the velic subsystem, there is a contrast between wide and unspecified. The value wide is attributed to nasal sounds. When a sound is oral, on the other hand, no value is specified. In the laryngeal subsystem of the vocal tract a distinction is once again drawn between wide and unspecified; wide is attributed to voiceless sounds. Voiced sounds are left unspecified.

\subsection{Gestural scores}

In AP the phonetic and phonological structure of an utterance is represented as a gestural score. A gestural score is a representation of the partly overlapping articulatory gestures that constitute the utterance. For example, the gestural score for the Norwegian word mat 'food' is shown as Fig. 1. ${ }^{3}$

The first segment has a closed CD at the labial CL. At the same time, it is associated with a wide velic gesture, i.e. this part of the utterance is nasal. It is unspecified for a glottalic gesture. In other words, the segment in question is voiced. In more traditional terms, this part of the utterance is a labial nasal stop.

The next part of the utterance is the syllable nucleus, which has a wide CD at the pharyngeal $\mathrm{CL}$-transcribed [a:] in the score. There is still no value for the glottalic aperture at this point in the score, indicating that the vocal folds are still vibrating, and since it has no value for the velic subsystem, it is an oral segment.

\footnotetext{
${ }^{1}$ Browman and Goldstein (1989: 228f) briefly mentioned a third dimension, constriction shape (CS), to account for distinctions such as apical versus laminal and central versus lateral; I return to the latter distinction below.

${ }^{2}$ Critical 'indicates that critical degree of constriction for a gesture at which some particular aerodynamic consequences could obtain if there were appropriate air flow and muscular tension' (Browman \& Goldstein, 1989:225).

${ }^{3}$ LIPS, tongue tip (TT), tongue body (TB), velic aperture (VEL) and glottalic (GLO) are names for tract variable sets. A tract variable set in the oral subsystem consists of a CL variable and a CD variable.
} 
The final consonant, transcribed as $[\mathrm{t}]$ in Fig. 1, is voiceless, as indicated by the value wide for the glottalic aperture. Moreover, it has a closed CD at the alveolar CL.

\subsection{Two stages in the acquisition of speech}

A fundamental property of speech is the coexistence of three different components: respiratory, phonatory, and articulatory. The articulatory component can be characterized by reference to a syllable structure (frame) and the segmental content filling this frame (MacNeilage, 1998). The physiologic process underlying the production of the syllable structure frame is the cyclic alternation between open and closed configurations of the vocal tract. Segmental content in combination with these cyclic alternations results in babbling, which forms the basis for the production of the first words around the child's first birthday (Locke, 1993; MacNeilage \& Davies, 2000; Vihman, 1996).

Within AP, the segmental part of the articulatory component is described in terms of articulatory gestures. Browman and Goldstein $(1989,204 f$.) identified two stages in a child's first attempts at producing words in the ambient language. The first stage is that of differentiation and tuning of individual gestures. When infants enter the stage of single word utterances, they have a restricted set of speech sounds in their repertoire. During the stage of differentiation and tuning, contrasts emerge which involve both CL (for example, dental vs. alveolar) and CD (for example, closed vs. critical). One example of an emerging CL contrast is the distinction in UEN between an apical and a palatal fricative [S, ç] (cf. Table 3 above) that emerges from a stage at which only [S] is used. One example of an emerging $C D$ contrast involves children at one stage using $[t]$ for both target $[t]$ and target [s], and then at a subsequent stage coming to differentiate between the two.

The second stage proposed by Browman and Goldstein (1989) is the stage of coordination of gestures. Even though infants and toddlers have a variety of articulatory gestures at their command, they have not yet mastered the often quite complex coordination of gestures that is necessary to produce target words. One example, from Studdert-Kennedy and Goodell's $(1995,76)$ subject Emma, is the utterance ['me:'nə] for the target word tomato, with a sequence of an alveolar [t], a labial [m], and an alveolar [t] gesture in the oral subsystem. The second of these gestures is coordinated with the value wide in the velic subsystem, resulting in a nasal consonant. Emma's attempt at this target word, ['me:'nə], contained a labial and an alveolar gesture in the oral subsystem, and two wide gestures in the velic subsystem. The velic gestures are not properly coordinated with the oral gestures.

\subsection{Gestural errors}

With respect to these two stages, it is possible to identify at least three different kinds of gestural errors in both child language (cf. Studdert-Kennedy \& Goodell, 1995, 81f.) and in disordered language (cf. Browman \& Goldstein, 1992:176f.): (1) errors of differentiation and tuning, (2) errors of coordination and sequencing, and (3) errors involving missing gestures.

Errors of differentiation and tuning can involve CL, CD, or both. Consider first a couple of examples among Hanna's utterances involving a consonantal constriction location error: 
LIPS

TONGUE TIP

TONGUE BODY

\section{closed labial}

VELUM

GLOTTIS

$[\mathrm{b}$ closed alveolar

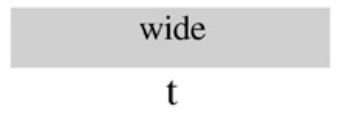

ə]

closed alveolar

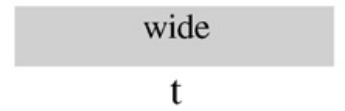

æ]

(b)

Fig. 2. (a) Gestural score for target word /'bøtə/ 'bucket'. (b) Gestural score for Hanna's attempt at the target word /'bøtə/ 'bucket' at 5;9.

(1a) ['katæ] for /'bøtə/ 'bucket' $(5 ; 9)$.

(1b) $[\operatorname{ly} \theta]$ for $/ \mathrm{y}: \mathrm{s} /$ 'light' $(9 ; 4)$.

In (1a), the initial segment in the target word has a labial CL; the corresponding segment in Hanna's word has a velar CL. In (1b), the final segment in the target word is a fricative with an alveolar CL [s], whereas in the corresponding word produced by Hanna there was a fricative with a dental CL $[\theta]$. The gestural score of the target pronunciation of / 'bøtə/ 'bucket' (cf. example (1a)) is shown in Fig. 2(a). Hanna's pronunciation of the same word is shown in Fig. 2(b) (only values for the consonants are represented in these figures).

Next, consider two examples with a CD error:

(2a) ['nitæ] for /'nisə/ 'gnome' $(9 ; 4)$.

(2b) ['tæk] for /'sek/ 'backpack' $(9 ; 4)$.

In both ( $2 \mathrm{a}$ and $\mathrm{b})$, the alveolar fricative in the target word appears as an alveolar stop in the corresponding word produced by Hanna. Fig. 3(a) and (b) give gestural scores for the target word in (2a) and Hanna's version of this word.

The example in (3) involves both an error in CD (labial approximant [v] instead of labial plosive /b/) and an error in CL (labiodental instead of bilabial):

(3) [vætว'i] for /batว'ri:/‘battery’ (7;0). 
LIPS

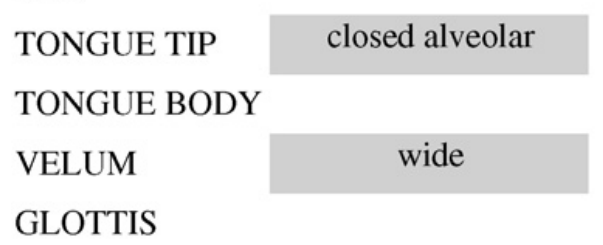

[n

(a)

LIPS

TONGUE TIP

closed alveolar

TONGUE BODY

VELUM

(b) [n

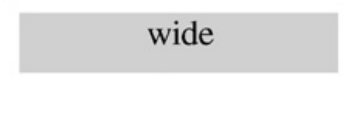

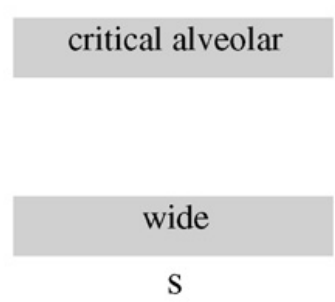

$\mathrm{S}$

ə]

closed alveolar

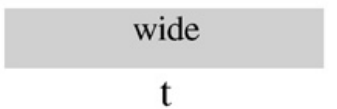

æ]

Fig. 3. (a) Gestural score for target word /'nisa/ 'gnome'. (b) Gestural score for Hanna's attempt at the target word /'nisa/ 'gnome' at 5;9.

Another subtype of $\mathrm{CD}$ errors are those involving a problem with a voice onset time (VOT). All of the Norwegian children examined by Kristoffersen (2003a, 2003b, 2004) had a problem with VOT, as the following examples (from Hanna's sample) show:

(4a) [pi] for /bi:l/ 'car' $(4 ; 6)$.

(4b) ['koko] for /'k' $\mathrm{h}^{\mathrm{h}} \mathrm{oka/}$ 'clock' (4;6).

(4c) [tak] for $/ \mathrm{t}^{\mathrm{h}} \mathrm{a}: \mathrm{k} /$ 'roof' $(9 ; 4)$.

In (4a), the initial voiced bilabial plosive of the target was reproduced by Hanna as a voiceless non-aspirated bilabial plosive. In ( $4 \mathrm{~b}$ and $\mathrm{c}$ ), the voiceless aspirated plosives of the target words were reproduced as voiceless non-aspirated plosives.

The second type of gestural error are gestures of coordination and sequencing. In errors of gestural coordination, the various gestures that constitute a target word are not properly coordinated, whereas errors of sequencing are errors where a gesture appears in the wrong place in a word. Example (5) is representative of Hanna's speech in which there were one or more errors of coordination and sequencing of gestures:

(5a) [mæ] for /van/ 'water' $(4 ; 6)$.

(5b) ['lon.æ] for /'nø.kl/ 'key' (7;0).

The target word in (5a) has two gestures in the oral subsystem, with labial and alveolar CLs. The second of these is accompanied by a wide velic gesture, producing the alveolar 
LIPS

\begin{tabular}{ll} 
TONGUE TIP & closed alveolar \\
\hline
\end{tabular}

TONGUE BODY

VELUM

GLOTTIS

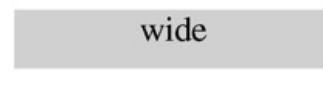

$\left[{ }^{\prime} n\right.$

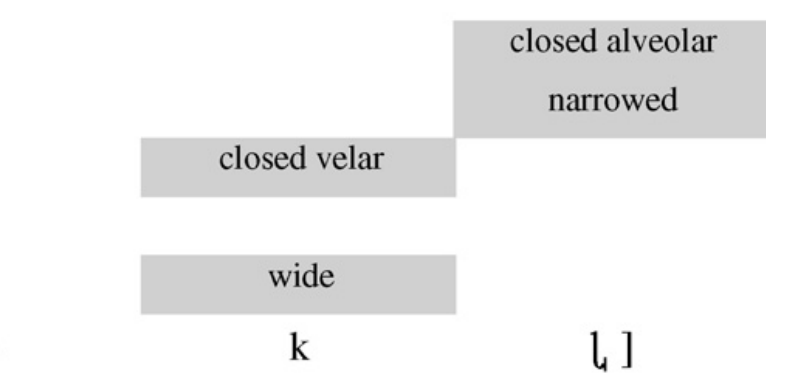

$\emptyset$

(a)

LIPS

TONGUE TIP

\begin{tabular}{|c|c|} 
closed alveolar \\
TONGUE BODY & narrowed \\
\hline
\end{tabular}

VELUM

GLOTTIS

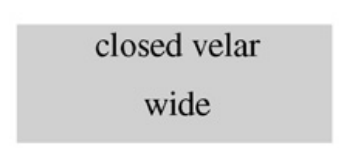

['1

o

]

$æ]$

(b)

Fig. 4. (a) Gestural score for target word /'nø.k / 'key'. (b) Gestural score for Hanna's attempt at the target word /'nø.k[/ 'key' at 7;0.

nasal consonant /n/. In Hanna's word the velic gesture is combined with the labial gesture (with bilabial for labiodental CL), resulting in the word [mæ]. The target in (5b) was produced by a coordination of the following consonantal gestures: closed alveolar $/ \mathrm{n} /$, closed velar $/ \mathrm{k} /$ and closed alveolar narrowed ${ }^{4} / /$ The first of these is combined with a wide velic gesture. Thus, all the gestures of the target word are present in Hanna's form. However, the gestures are poorly coordinated. In addition, there is an error of sequencing, in that the final /l/ of the target word appears as the initial segment in Hanna's word. Gestural scores for both the target pronunciation and for Hanna's pronunciation of the word in (5b) are shown in Fig. 4(a) and (b).

Another set of examples involving errors of coordination is shown in (6), all from 9;4, where an epenthetic vowel appears between the two consonants in a two place target consonant group:

(6a) [po'lot] for /blomst/ 'flower' $(9 ; 4)$.

(6b) ['æpələ] for /'eplə/ 'apple' $(9 ; 4)$.

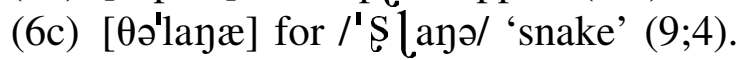

(6d) [po 'lo] for /'blo:/ 'blue' $(9 ; 4)$.

\footnotetext{
${ }^{4}$ The term narrowed refers to a value of constriction shape involved in the production of laterals. The aspect of laterals referred to by this term is a 'narrowing of the tongue volume, so that it is pulled away from the sides of the mouth’ (Browman \& Goldstein, 1989, 228; see also footnote 1 above.).
} 
In (6a) there is a sequence [pol] in Hanna's form, which corresponds to a target sequence $/ \mathrm{b} /$. In the target sequence, the gestures making up the two consonants are coordinated in such a way that there is a certain overlap; the onset of the TT gesture for /// begins before the offset of the LIPS gesture for /b/. In Hanna's word, both gestures were present, but they were not coordinated according to the rules of the target language, resulting in an epenthetic vowel. Hanna's forms in $(6 \mathrm{~b}-\mathrm{d})$ can be analysed in a parallel fashion. Note than in all four examples the epenthetic vowel share one or more features with the root vowels.

Missing gestures make up the third type of gestural errors. In the most extreme case, all gestures constituting a segment are missing, as in the following examples:

(7a) [pi] for /bi:l/ 'car' $(4 ; 6)$.

(7b) $[\mathrm{pæ}]$ for /bal/ 'ball' $(4 ; 6)$.

(7c) [' $\mathrm{tæ}]$ for /'k ' ru:nə/ 'crown' $(4 ; 6)$.

In $(7 \mathrm{a}, \mathrm{b})$ all of the gestures that constitute the lateral approximant of the target word are missing, and in (7c) all gestures constituting all consonants are missing. I return to cases like these in Section 5.4.

In other cases, only some of the gestures constituting a segment are missing, cf. (8)-(9):

(8a) ['hænæ] for /'tæjnə/ 'draw'(4;6).

(8b) [hul] for /fut:1/ 'bird' $(9 ; 4)$.

(8c) [hu $\theta$ ] for /d $\mathrm{S} /$ 'shower' $(9 ; 4)$.

(9a) ['pætæ] for /'bamsə/ 'teddy bear' $(7 ; 0)$.

(9b) ['vituə] for /'vindtə/ 'window-the' $(9 ; 4)$.

In the forms in (8), the first segment in Hanna's words is [h], with a glottal gesture, but no oral gesture, as is the case with the corresponding sound in the target word.

In the two examples in (9), both target words contain a sequence of an oral and a nasal consonant medially, that is, there is a wide velic gesture associated with the second consonant of this cluster. In Hanna's forms, on the other hand, there is no wide velic gesture. In (9a), there is also a wrong CD value for the target [s], which is closed in Hanna's word, instead of critical, as it should be.

To show that Hanna's consonant productions developed during the period under investigation for this study I present in Fig. 5 three gestural scores, which represent Hanna's attempts at the various points of observation at pronouncing the target word is /i:s/ 'ice cream', along with a gestural score for the target word itself.

In summary, both early words of normally developing children and words produced by individuals with a language disorder can be characterised in terms of three different types of gestural deviations from target words (or 'errors'), errors of differentiation and tuning, errors of coordination and sequencings, and missing gestures. In Hanna's case, errors from all three categories contributed to her disordered speech. However, the impact of each error type varies with age, and, as we shall see below, there was also clear improvement in many aspects of her speech during the period I have followed her development. 
LIPS

TONGUE TIP

TONGUE BODY

VELUM

GLOTTIS

(a)

LIPS

TONGUE TIP

TONGUE BODY

VELUM

GLOTTIS

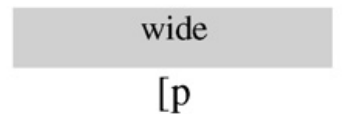

$[\mathrm{i}:$

wide

s]

narrow palatal

critical alveolar

narrow palatal

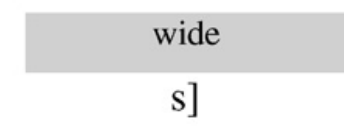

closed labial

[p

(b)

LIPS

TONGUE TIP

TONGUE BODY

narrow palatal

VELUM

GLOTTIS

[i:

(c)

LIPS

TONGUE TIP

closed alveolar

TONGUE Body

VELUM

GLOTTIS

[i:

wide

(d)

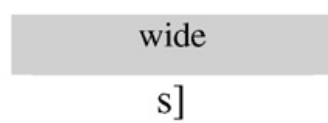

Fig. 5. (a) Gestural score for Hanna's attempt at the target word /i:s/ 'ice cream' at 4;6. (b) Gestural score for Hanna's attempt at the target word /i:s/ 'ice cream' at 5;9. (c) Gestural score for Hanna's attempt at the target word /i:s/ 'ice cream' at 7;0 and 9;4. (d) Gestural score for target word /i:s/ 'ice cream'.

\section{Method}

\subsection{The subject}

The subject of this study, Hanna, has been raised in a monolingual Norwegian-speaking environment. She is a second child, and was diagnosed with CCS at 6 weeks of age. 
Diagnosis was suspected on the basis of her cry, and confirmed by chromosomal analysis, which demonstrated a de novo terminal deletion with a breakpoint at 14.2.

Hanna received physiotherapy twice a week from 3 through 11 months of age. After that time, she received physiotherapy on a more irregular basis. She has been systematically taught sign language since she was 3 months of age, mostly in kindergarten and school, but also to some extent at home. Since she was 6 years old she has attended a special class where signing is used regularly. She has received speech therapy since she was 8 years old; Hanna's target language is UEN (described in Section 2).

\subsection{Materials}

An elicitation task was developed based on the author's knowledge of Hanna's production vocabulary. The task was given to her four times (at ages $4 ; 6,5 ; 9,7 ; 0$, and 9;4), and contained approximately100 test items (the exact number of items depended on the point of observation). The data at 4;6,5;9, and 7;0 were originally collected for the studies reported by Kristoffersen (2003a, 2003b), whereas the data at 9;4 were collected for the present study. The same test items were used at 4;6, 5;9, and 7;0. At 9;4, a more thoroughly revised set of items was used, which were more in accordance with her production vocabulary at that age. As far as possible, the pictures and objects in the elicitation task were chosen so that all target phonemes in all positions in words were covered. In addition, items were included that elicited words with two place consonant clusters. ${ }^{5}$

Objections can be raised both to this method of data collection (cf. Grunwell, 1985, Chap. 2) and to the size of the samples. First, speech samples containing spontaneous speech are normally considered better data than samples elicited by a naming task. However, since Hanna produced so few spontaneous utterances, collecting spontaneous speech data would have been infeasible. Second, Grunwell (1985) considers a sample of 100 different words to be a minimum, but recommends a sample twice as large, 'in order to obtain sufficient data to record the child's realization of the majority of the adult targets more than once and thus to reveal the presence of any clinically significant variability [...]'. Clearly, this is a reasonable recommendation. However, limitations in Hanna's expressive vocabulary made it difficult to obtain even as many as 100 different words, not to mention twice as many. Thus, the sample size of approximately 100 words used in this study may be considered problematic, but defendable given the language skills of the subject.

\subsection{Procedure}

In order to elicit the test items, Hanna was shown a photo, a drawing, or a toy representing the various items, and then asked, "What is this?" Sometimes it was necessary to provide her with additional information to elicit the items. At the same time, care was taken to avoid using the target words immediately before showing Hanna the pictures and objects included in the test material.

\footnotetext{
5 As mentioned in Section 2, also three place consonants clusters are found in UEN. Since Hanna had no clusters at all at 4;6, 5;9, and 7;0, and no three place and only a few two place clusters at 9;4, items that aimed at eliciting three place clusters were not included in the material.
} 
The test sessions were recorded into a Sony MiniDisc recorder, using an electret condenser microphone. Hanna and the author were seated beside each other at a table upon which the test materials and the microphone were placed. The microphone was placed no more than $40 \mathrm{~cm}$ from Hanna.

\subsection{Data analysis}

All samples were given a narrow IPA transcription by the author. Approximately onefifth $(20.5 \%)$ of the utterances at age $4 ; 6$ were also transcribed by a second transcriber. Agreement between the two transcribers was $87.5 \%$. In cases of disagreement, the author's transcription was used for analysis.

From all the forms produced by Hanna at each point during the observation period, the same subset of 36 forms was selected for analysis (see the Appendix A for a complete list of these items). ${ }^{6}$ Thus, a total of 144 forms were analyzed. The error rate was measured in terms of percent consonants correct (PCC) and percent consonant clusters correct (PCCC). The PCC measure were based on the PCC-R of Shriberg et al. (1997), where only deletions and substitutions were scored as incorrect, whereas distorted consonants were scored as correct. For example, plosives with the correct place of articulation (CL), but wrong VOT were scored as correct. Also, the target fricative /s/ was pronounced in a number of ways; as long as the manner of articulation was fricative it was scored as correct. ${ }^{7}$

Hanna's error patterns were analyzed in terms of the three types of articulatory errors discussed above (i.e., missing gestures, errors of differentiation and tuning, and errors of coordination and sequencing).

\section{Results}

When she was 9;4, Hanna produced 14 different consonant phones, as shown in Table 6. This is the same number of consonants she produced at age $7 ; 0$, one more than at age $5 ; 4$, and three more than at age 4;6. The majority of missing consonants were fricatives, even though the number of fricatives slowly increased. Furthermore, at no point did Hanna make a distinction between apical and laminal phones, which are part of the target language inventory (cf. Table 3).

\subsection{Percent consonants correct and percent consonant clusters correct}

Percent consonant correct and PCCC were measured at all four points during the observation period. Percent consonant clusters correct was measured in word-initial position only. The findings are presented in Table 7.

\footnotetext{
${ }^{6}$ These 36 forms were the forms which appeared at all four points of observation. Thus, forms which were missing in one or more of the four samples were not selected for analysis.

${ }^{7}$ Shriberg et al. (1997) strongly recommends basing the PCC scores on a conversational speech sample, as these are taken to be linguistically and psychometrically more robust than, e.g., samples from elicitiation tasks. Since a conversational speech sample would be impossible in the case of Hanna (cf. Section 4.3), I have chosen to base the PCC scores on the available data instead.
} 
Table 6

Hanna's consonant inventory at 9;4

\begin{tabular}{lcccc}
\hline & Labial & Coronal & Dorsal & Glottal \\
\hline Plosive & $\mathrm{p}$ & $\mathrm{t}$ & $\mathrm{k}$ & \\
Nasal & $\mathrm{m}$ & $\mathrm{n}$ & $\mathrm{y}$ & \\
Fricative & $\mathrm{f}$ & $\theta, \mathrm{s}$ & & $\mathrm{h}$ \\
Approximant & $\mathrm{v}$ & 1 & $\mathrm{j}$ & \\
Other & & & $\mathrm{R}$ & \\
\hline
\end{tabular}

Table 7

Percent consonants correct and percent consonant clusters correct

\begin{tabular}{lcccc}
\hline & $4 ; 6(\%)$ & $5 ; 9(\%)$ & $7 ; 0(\%)$ & $9 ; 4(\%)$ \\
\hline PCC & 22.8 & 28.9 & 41.0 & 69.9 \\
PCCC & 0 & 0 & 0 & 25 \\
\hline
\end{tabular}

\subsection{Number of errors (total and per word)}

In general, there was less variation, fewer omissions of segments, fewer cluster simplifications, and fewer substitutions at 9;4 than at 4;6, 5;9, and 7;0. Table 8 gives the total number of errors and the average number of errors per word for all four time points of observation.

A one-way ANOVA with the number of errors as the dependent variable and age of observation as a fixed factor revealed a significant difference between the average number of errors per word at each time point of observation $(F=3.929 ; p=0.009)$, and post-hoc analyses showed that there were significantly fewer errors at $9 ; 4$ than at 5;9 $(p=0.02)$ and $4 ; 6(p=0.01)$.

\subsection{Quantitative relationship between error types}

In Section 3.3, deviations from target words in children's speech and disordered speech were characterized in terms of three types of errors: (1) errors of differentiation and tuning, (2) errors of coordination and sequencing, and (3) errors involving missing gestures. Fig. 6 gives the proportion of the three error types at each of the four ages.

At the three first points of observation, the majority of errors were missing gestures, followed by errors of differentiation and tuning. At 9;4, the most frequent error type was

Table 8

Total number of errors and average number of errors per word

\begin{tabular}{lll}
\hline Age & Number of errors & Average number of errors per word \\
\hline $4 ; 6$ & 84 & 0.80 \\
$5 ; 9$ & 72 & 0.69 \\
$7 ; 0$ & 62 & 0.59 \\
$9 ; 4$ & 45 & 0.43 \\
\hline
\end{tabular}




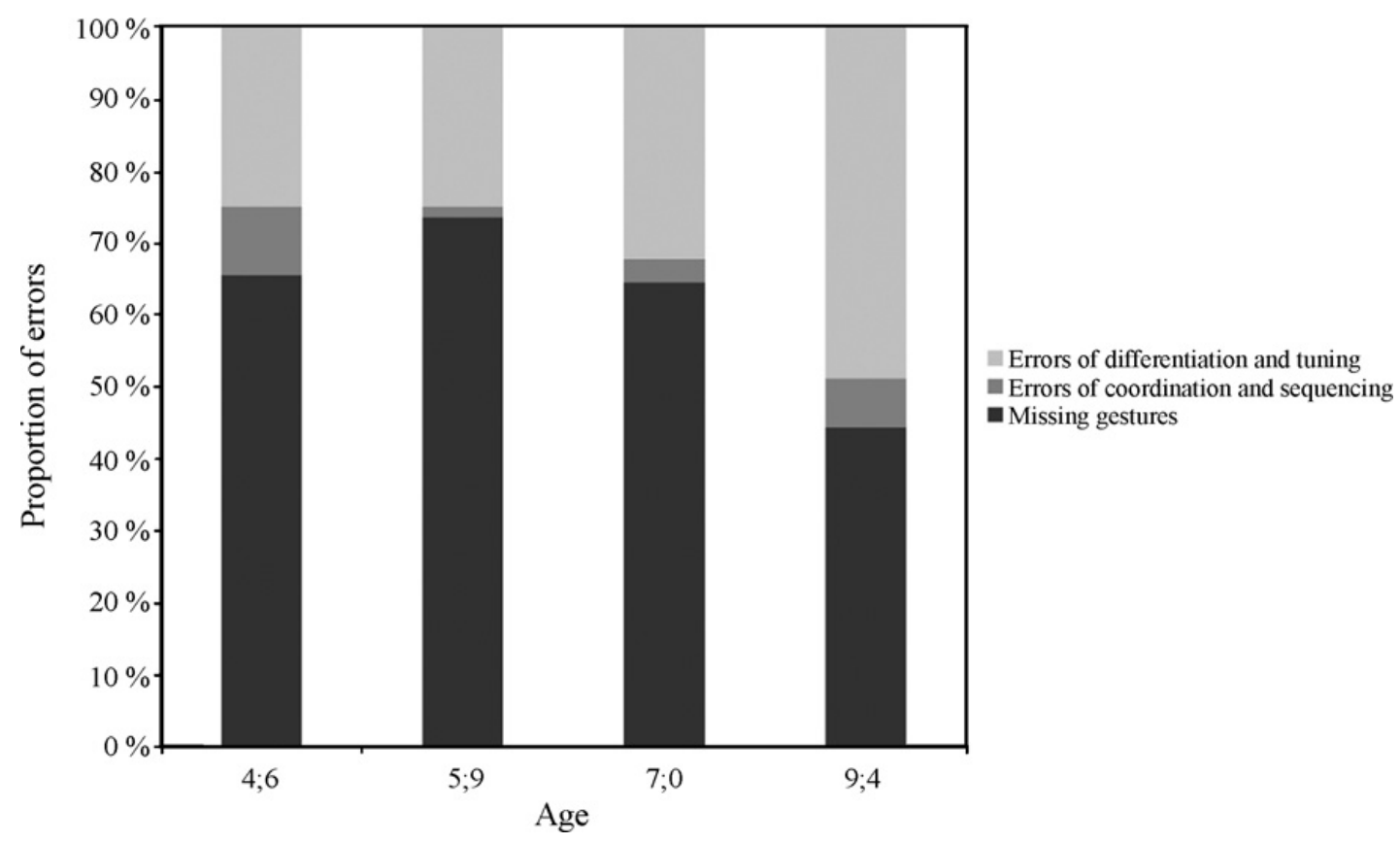

Fig. 6. All error types across all ages.

errors of differentiation and tuning. Furthermore, whereas the number of missing gestures decreased from $5 ; 9$, the number of errors of differentiation and tuning increased. As can be seen from Fig. 6, the number of errors of coordination and sequencing was low at all four points of observation.

Fig. 7 shows that errors of differentation and tuning were relatively stable across all points of observation, ranging from 21 at age 4;6 to 22 at age 9;4. No significant betweengroup difference was found for this error type.

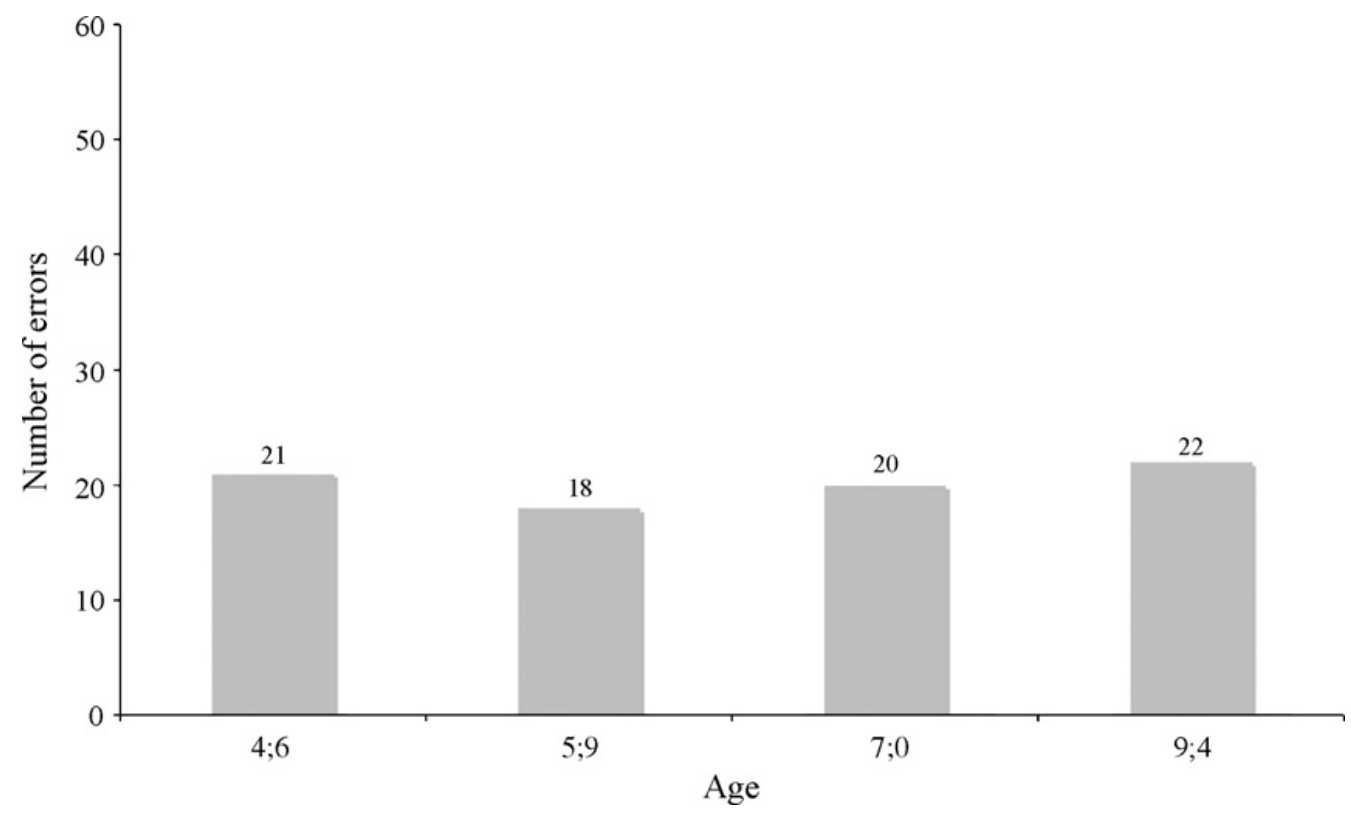

Fig. 7. Errors of differentiation and tuning. 


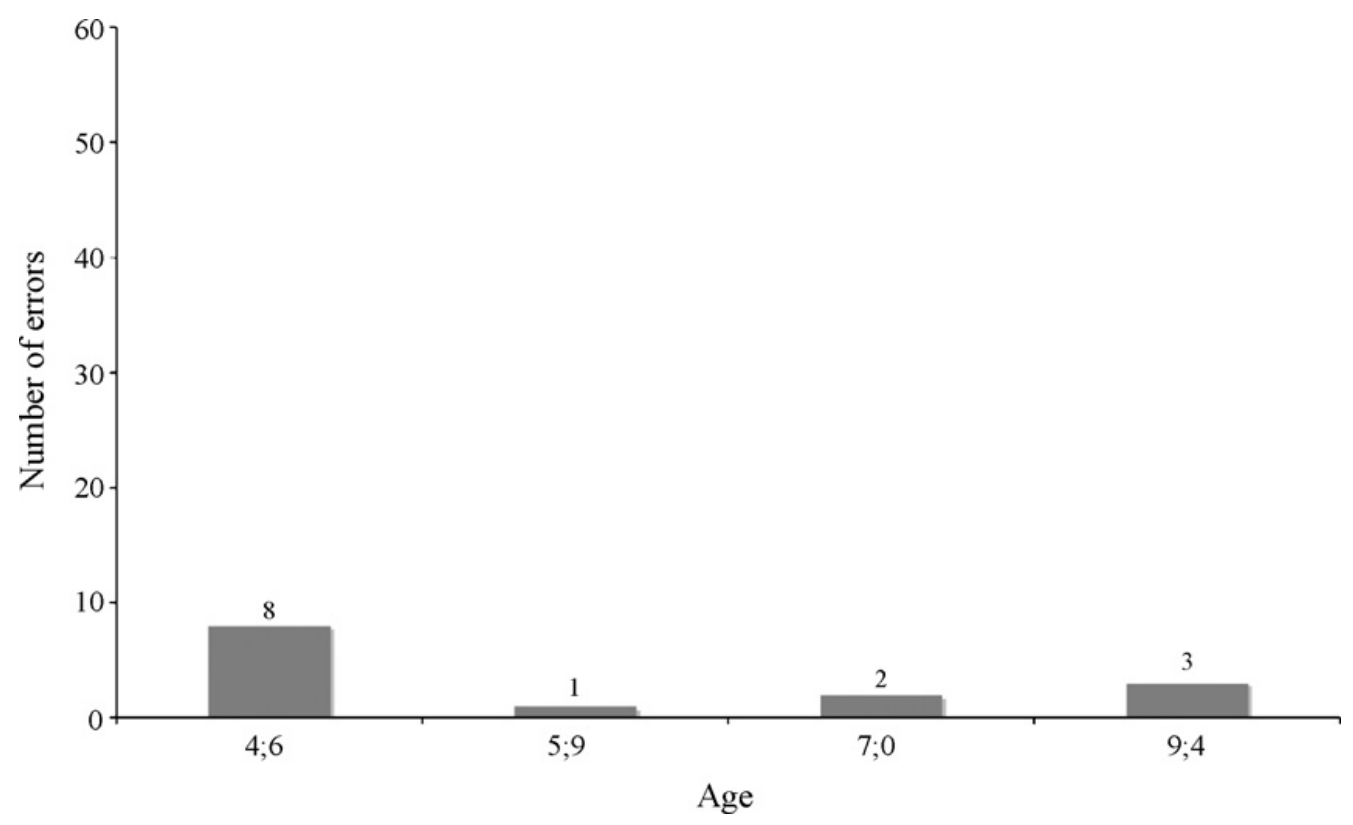

Fig. 8. Errors of coordination and sequencing.

The number of errors of coordination and sequencing was comparatively low at all points of observation, as can be seen in Fig. 8. In this group, there was a significant between-group difference $(F=2.728 ; p=0.000)$. Post-hoc analyses showed significant differences between age 4;6 on the one hand, and ages 5;9 and 7;0 on the other.

Missing gestures were the most common type of error at all four points of observation, as shown in Fig. 9. In this category there was a significant between-group difference $(F=10.701 ; p=0.047)$. Posthoc analyses revealed significant differences between errors at $4 ; 6$ on the one hand and at 7;0 and 9;4 on the other, between errors at $5 ; 9$ and $9 ; 4$, and between errors at 7;0 and 9;4.

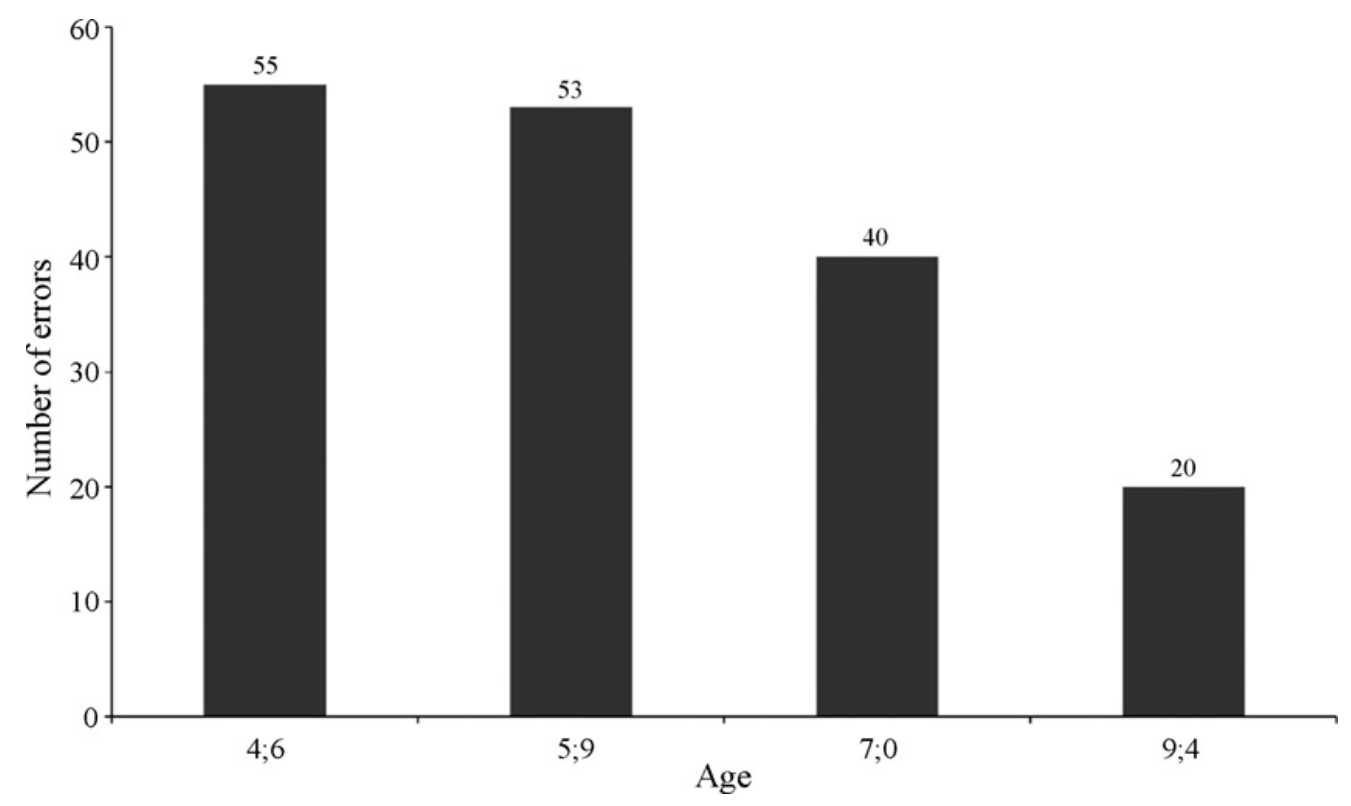

Fig. 9. Missing gestures. 


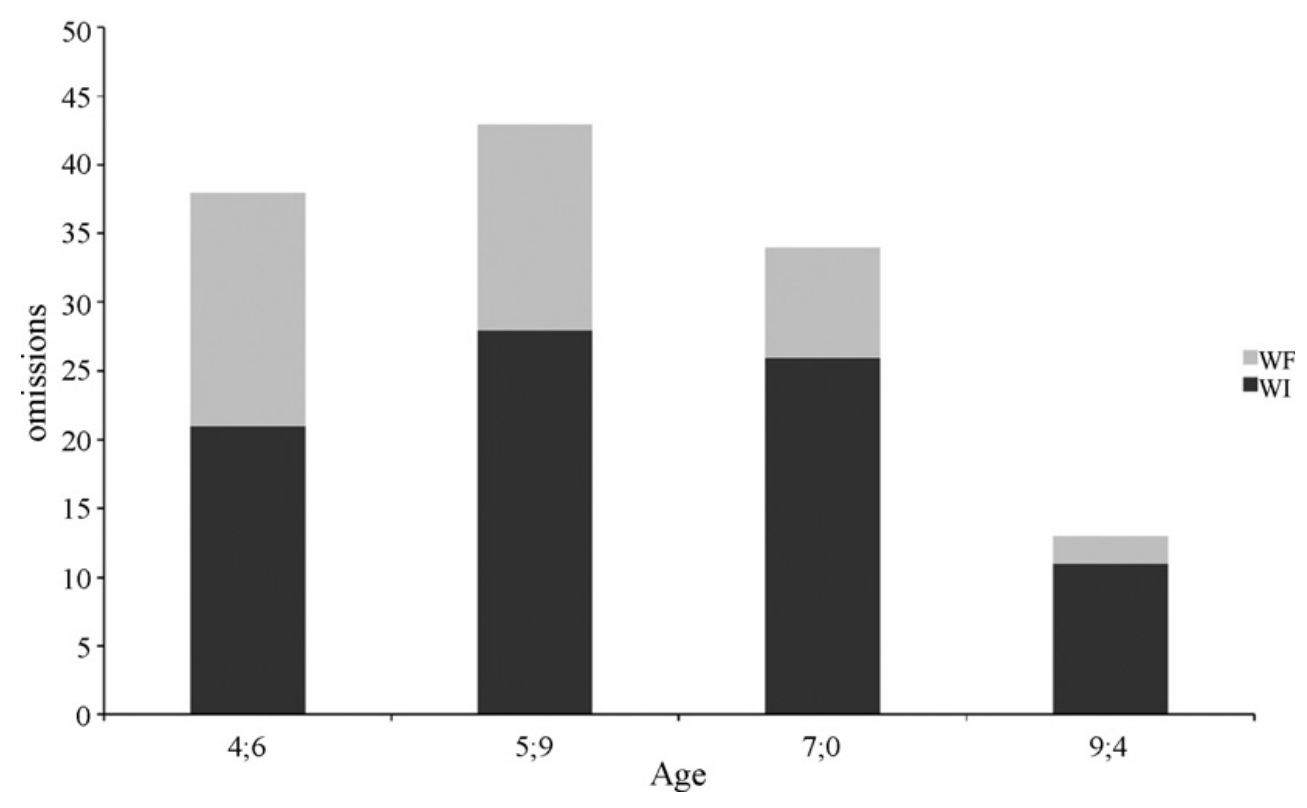

Fig. 10. Omission of segments in word-initial and word-final position.

\subsection{Omission of segments}

At all four ages, Hanna frequently omitted all gestures making up a segment. Moreover, there was a difference between word-initial and word-final positions in this respect (see Fig. 10). In the 36 words selected for analysis at 4;6, there were some more omitted segments in word-initial than in word-final position (21 against 17). At 9;4, on the other hand, omitted segments in the word-initial position were still relatively frequent $(n=11)$, whereas there were only two word-final omissions of whole segments.

\section{Discussion}

This study was a detailed examination of the development of error rates and error patterns in the consonant productions of one Norwegian girl with CCS. Previous research had established that the speech of persons with this syndrome was characterized by frequent omissions and substitutions (Cornish et al., 1999; Schlegel et al., 1967; Sparks and Hutchinson, 1980), and small consonant inventories as compared to those of normally developing children (Kristoffersen, 2003b, 2004). The present study supported these previous findings, and also provided a detailed qualitative and quantitative analysis of error rates and error types in a longitudinal perspective.

\subsection{Percent consonants and consonant clusters correct}

Error rates as measured by PCC and PCCC were high at all four ages included in this study. The PCC varied from $22.8 \%$ at $4 ; 6$ to $69 \%$ at $9 ; 4$. Unfortunately, no studies measuring PCC in typically developing children and children with other speech and language disorders than CCS learning Norwegian exist, making it impossible to compare 
Hanna's performance with that of other groups in the same language. However, there is one study measuring PCC in three groups of children learning Swedish, a Germanic language which is closely related to Norwegian. Hansson and Nettelbladt (2002) investigated speech and language skills in 14 children with SLI (mean age, 4;11), 14 language-matched controls (mean age, 2;11), and 14 age-matched controls (mean age 4;11). The PCC for these three groups were $80.10 \%$ for children with SLI, $87.67 \%$ for the language-matched controls, and $98.69 \%$ for the age-matched controls. These findings give an indication of the severity of Hanna's problems in this area.

The PCCC measures indicated an even greater delay. At no point of observation did Hanna produce target clusters correctly. Her strategy was either to delete one or both consonants (e.g., ['patæ] for /'spadə/ for 'shovel' and /æy/ for /stæjn/'stone'). At 9;4 she also produced forms with two consonants, but with an epenthetic vowel between them, e.g., [po 'lo] for /blo:/ 'blue', and [fæ'læk] for /flag/ 'flag'. These facts indicate that she mastered obstruent+sonorant clusters somewhat better than sibilant+stop clusters.

Kristoffersen and Simonsen (2006) investigated the acquistion of word-initial twoelement consonant clusters in typically developing 2- to 3-year-old children learning Norwegian, and found that the PCCC for all clusters were 78\%. Moreover, obstruent+sonorant clusters were mastered significantly better $(81 \%)$ than sibilant+stop clusters $(75 \%)$. In other words, Hanna's performance in this respect throughout the period covered by this study was much poorer than normally developing children between 2 and 3 years of age. On the other hand, she followed the normally developing children in mastering obstruent+sonorant clusters better than sibilant+stop clusters.

\subsection{Persistence of error patterns, but also progress}

Earlier studies of speech and language skills in CCS have noted omissions and substitutions in general, without explicating the nature and extent of these. The current study expanded on this previous research by describing various kinds of misarticulations in detail in terms of three different types of articulatory errors: (1) errors of differentiation and tuning, (2) errors of coordination and sequencing, and (3) missing gestures. In Hanna's case these errors seem to have persisted. As already noted, persistence of error patterns, and lack of progress, are characteristic properties of disordered phonologies (Stoel-Gammon, 1991), and one of the questions addressed by the present study was whether there was only persistence of errors in Hanna's speech, or whether there was also progress.

The study revealed that Hanna made errors in all three categories. However, there were some differences between the three categories. Consider first missing gestures. These amounted to more than $50 \%$ of all errors in the samples of her speech from the observation points at $4 ; 6,5 ; 9$, and 7;0. At 9;4, this type still made up a considerable share of all errors, but now only $44 \%$. At this point, there were more errors of differentiation and tuning (49\% of all errors at this age). In other words, evaluated on the basis of missing gestures, error patterns in Hanna's speech persisted. However, it was found that even though the share of missing gestures was high at all ages, there was still a significant decrease in this category between $4 ; 6$ and 7;0/9;4, indicating some amount of progress.

Also errors of differentiation and tuning persist. There were 21 errors of this type at age $4 ; 6$ and 22 at age 9;4. In this case no significant differences between the four points of 
observation were found. In other words, for this error type there was persistence, but no progress.

At all points of observation there were few errors of coordination and sequencing. However, a significant decrease in the number of these errors was found between $4 ; 6$ and $5 ; 9 / 7 ; 0$, once again indicating progress to some extent.

In summary, for the most part, Hanna's articulatory errors persisted throughout the period under investigation for this study. But, as we have seen, there are also some signs of progress, as the number of missing gestures and errors of coordination and sequencing decreased somewhat during the period.

\subsection{Omission of segments in word-initial and word-final position}

Another finding of this study was that Hanna frequently omitted segments. For example, at age $4 ; 6$ there were 21 omissions in the word-initial position in the 36 words selected for analysis. At age 9;4, the number of omissions had decreased to 11 . Also, there were differences relating to word position and age. At all four points of observation, she omitted segments in word-initial position more often than in word-final position. However, whereas at age 4;6 there were almost as many omitted segments word-finally as word-initially, at age 9;4 there were almost no omissions in word-final position, but still many omitted segments in word-initial-position.

Again, these results indicate that Hanna's language was extremely delayed. For example, the 2- to 3-year-old normally developing children who participated in the study reported on by Kristoffersen and Simonsen (2006) omitted word-initial consonants in about $18 \%$ of the words in the database. However, Hanna's deletion patterns were also deviant in the sense that the most common pattern among normally developing children is omission of word-final consonants, whereas omission of wordinitial consonants is uncommon (Small, 2005). Note also that this pattern of word-initial omissions persists.

\subsection{Issues for further research}

This paper reported a case study of consonant productions in one Norwegian girl with CCS through ages 4;6-9;4. It was shown that she had many articulation errors throughout the period she was followed. Furthermore, these errors fell into three main categories: (1) errors of differentiation and tuning, (2) errors of coordination and sequencing, and (3) missing gestures. Finally, segments were frequently omitted. On the other hand, the study also showed that the number of errors decreased as she grew older, resulting in a more accurate rendition of the target words, and consequently more intelligible language.

This study raises a number of issues for future research. First of all, since this was a single-case study, the need for studies including more participants should be obvious. A problem here is of course the scarcity of persons with this syndrome. Furthermore, there appear to be extensive developmental variation among persons with CCS, and for that reason larger-scale group studies may appear to be impossible. An option is of course multi-case studies. 
Second, the present study leaves the question unsettled as to what extent the articulation errors are relating to the phonological structure of Norwegian, and to what extent they can be ascribed to the delayed motor or cognitive development observed in persons with CCS. Here, investigations of other languages than Norwegian are needed, as well as studies of the relationship between speech and language, motor development, and non-verbal cognitive development.

\section{Acknowledgements}

I am grateful to Sarah Hawkins, Jan Hognestad, Ray D. Kent, Gjert Kristoffersen, Marianne Lind, Inger Moen, and Hanne Gram Simonsen for useful comments on earlier versions of this paper; any errors are mine.

\section{Appendix A}

Words selected for analysis (in IPA transcription).

\begin{tabular}{|c|c|c|c|c|}
\hline Target & $4 ; 6$ & $5 ; 9$ & $7 ; 0$ & $9 ; 4$ \\
\hline Ape 'monkey' & 'рæрæ & 'арә & 'арæ & 'арæ \\
\hline Appelsin 'orange' & $\mathrm{i}$ & 'æpæ'i & 'æpæ'in & apæ'in \\
\hline Ball 'ball' & $\mathrm{pæ}$ & pæl & pal & pal \\
\hline Bil 'car' & pi & pi & pil & pil \\
\hline Blå 'blue' & \# & өə & pa & po'lo \\
\hline Brus 'limonade' & $h t$ & $\Theta$ & pet & put \\
\hline Egg 'egg' & $æ j$ & $æ c$ & $æ c$ & $æ k$ \\
\hline Eple 'apple' & 'рæрæ & 'æpæ & 'æрæ & 'æpələ \\
\hline Flagg 'flag' & æj & 'acə & læc & fæ'læk \\
\hline Gaffel 'fork' & 'сæcə & 'æti & 'æpəl & 'kæfəl \\
\hline Glass 'glass' & $\mathrm{ca}$ & $æ ?$ & $æ c$ & læk \\
\hline Gul 'yellow' & u & \# & ul & kul \\
\hline Hest 'horse' & $\mathrm{i}$ & æt & æt & hæt \\
\hline Hjelm 'helmet' & 'mə'mæ & '?æm & $æ m$ & æm \\
\hline Hund 'dog' & $h t$ & 'æөæ & u & un \\
\hline Huske 'swing; remember' & 'hцæ & 'eke & 'uki & 'uki(kə jetə) \\
\hline
\end{tabular}




\section{Appendix A (Continued)}

\begin{tabular}{|c|c|c|c|c|}
\hline Target & $4 ; 6$ & $5 ; 9$ & $7 ; 0$ & $9 ; 4$ \\
\hline Hvit 'white' & hi & $\mathrm{i}$ & it & vit \\
\hline Is 'ice' & pi & $\mathrm{i}$ & it & it \\
\hline Jus 'juice' & $U$ & \# & ut & ut \\
\hline Klokke 'clock' & kokə & 'koko & 'kokæ & 'lokæ \\
\hline Kniv 'knife' & $\mathrm{i}$ & $\mathrm{i}$ & ni & niv \\
\hline$K u$ 'cow' & $\mathrm{m}$ & $\mathrm{m} \theta$ & 'vo & $\mathrm{k} \partial \mathrm{u}$ \\
\hline Melk 'milk' & mæl & məl & mel & malk \\
\hline Nøkkel 'key' & a'yæ & 'ayæ & 'loךæ & 'nokæl \\
\hline Pappa 'Daddy' & 'рæрæ & 'papa & 'papa & 'papa \\
\hline Paraply 'umbrella' & pei & 'pa'pi & 'pæjæ'py & 'paja'pi \\
\hline Penge 'money' & 'ə઼æ & 'æฑæ & 'æyə & 'pæyæ \\
\hline Rød 'red' & \# & 'өə & 'øœ & çæ \\
\hline Sekk 'sack' & $\mathrm{cæ}$ & $æ c$ & æcç & tæk \\
\hline Siv name & $\mathrm{i}$ & $\mathrm{i}$ & $\mathrm{i}$ & $\operatorname{siv}$ \\
\hline$S k i$ 'ski' & $\mathrm{i}$ & $\mathrm{i}$ & $\mathrm{i}$ & si \\
\hline Skøyter 'ice skates' & œæ & 'æka & 'utæ & 'øtæ \\
\hline Spade 'showel' & 'рæрæ & 'patæ & 'pate & 'patæ \\
\hline Stein 'stone' & yæ & æy & æy & tæy \\
\hline Sykkel 'bike' & 'piæ & 'icæ & 'icæl & 'sətkæl \\
\hline
\end{tabular}

\section{Appendix B. CE questions}

1. Cri du chat syndrome (CCS) is a rare genetic disorder with an estimated incidence:
A. between 1:20,000 and 1:50,000 births
B. between $1: 50,000$ and $1 ; 60,000$ births
C. of more than $1: 150,000$ births
D. of less than 1:15,000 births

2. The measures of consonant productions in this study consists of:
A. Percent Consonants Correct
B. Percent Consonant Clusters Correct 
C. Error rate and error patterns

D. Percent Consonants Correct, Percent Consonant Clusters Correct, Error rate, and Error patterns.

3. The target language of the subject of this study was:
A. Icelandic
B. Danish
C. Norwegian
D. Swedish

4. The theoretical framework used in this study was:
A. Metrical phonology
B. Articulatory phonology
C. Optimality theory
D. Underspecification theory

5. The results of this study showed that:
A. the subject's consonant productions were delayed but not deviant as compared to normally developing children
B. the subject's consonant productions were deviant but not delayed as compared to normally developing children
C. the subject's consonant productions were both delayed and deviant as compared to normally developing children
D. the subject's consonant productions were neither delayed nor deviant as compared to normally developing children

\section{References}

Baird, Samera M., Campbell, Dennis, Ingram, Rebecca, \& Gomez, Caroline. (2001). Young children with Cri-Du-Chat: Genetic, developmental, and behavioral profiles. Infant-Toddler intervention, 11(1), 1-14.

Byrd, D. (2003). Frontiers and challenges in articulatory phonology. In M. J. Solé, D. Recasens, \& J. Romero (Eds.), In Proceedings from the 15th international congress of phonetic sciences (pp. 89-92). Adelaide, Australia: Causal Productions Pty Ltd.

Browman, C. P., \& Goldstein, L. (1989). Articulatory gestures as phonological units. Phonology, 6, $201-251$.

Browman, C. P., \& Goldstein, L. (1992). Articulatory phonology: An overview. Phonetica, 49, 155-180.

Carlin, M. E. (1990). In W. I. Fraser (Ed.), The improved prognosis in Cri-du-chat (5p-) syndrome (pp. 64-73). London/Routledge: Key Issues in Mental Retardation Research.

Collins, M. S. R., \& Cornish, K. (2002). A survey of the prevalence of sterotypy, self-injury and aggression in children and young adults with Cri du chat syndrome. Journal of Intellectual Disability Research, 46, 133-140.

Cornish, K., Bramble, D., Munir, F., \& Pigram, J. (1999). Cognitive functioning in children with typical cri du chat (5p-) syndrome. Developmental Medicine and Child Neurology, 41, 263-266.

Cornish, K., \& Munir, F. (1998). Receptive and expressive language skills in children with cri du chat syndrome. Journal of Communication Disorders, 31, 73-81.

Cornish, K., \& Pigram, J. (1996). Developmental and behavioural characteristics of cri du chat syndrome. Archives of Disease in Childhood, 75, 448-450.

Grunwell, P. (1985). PACS. Phonological assessment of child speech. San Diego: College Hill Press.

Hansson, K., \& Nettelbladt, U. (2002). Assessment of specific language impairment in Swedish. Logopedics Phoniatrics Vocology, 27, 146-154.

Kristoffersen, G. (2000). The phonology of Norwegian. Oxford: Oxford University Press.

Kristoffersen, K. E. (2003a). Development of consonants and vowels in a child with cri du chat syndrome. Journal of Multilingual Communication Disorders, 1, 194-200. 
Kristoffersen, K. E. (2003b). Phonological development in a child with cri du chat syndrome. Nordlyd [On-line serial], 31 (http://www.ub.uit.no/baser/nordlyd/viewissue.php?id=3\#Articles).

Kristoffersen, K. E. (2004). Consonant productions in three children with cri du chat syndrome. In B. E. Murdoch, J. Goozee, B.-M. Wehlan, \& K. Docking (Eds.), IALP congress-proceedings. Australia: Speech Pathology.

Kristoffersen, K. E. (2007). Norwegian speech acquisition. In S. McLeod (Ed.), The international guide to speech acquisition. Thomson Delmar Learning.

Kristoffersen, K. E. (submitted for publication). Speech and language development in cri du chat syndrome-a critical review.

Kristoffersen, K. E., \& Simonsen, H. G. (2006). The acquisition of \#/s/C clusters in Norwegian. Journal of Multilingual Communication Disorders, 4, 231-241.

Locke, J. L. (1993). The child's path to spoken language. Cambridge, MA: Harvard University Press.

MacLeod, S., van Doorn, J., \& Reed, V. A. (2001). Consonant cluster development in two-year-olds: General trends and individual difference. Journal of Speech, Language, and Hearing Research, 44, 1144-1171.

MacNeilage, P. F. (1998). The frame/content theory of evolution of speech production. Behavioral and Brain Sciences, 21, 499-546.

MacNeilage, P. F., \& Davies, B. L. (2000). On the origin of internal structure of word forms. Science, 288, 527-531.

Niebuhr, E. (1978). Cytologic observations in 35 individuals with 5p-karyotype. Human Genetics, 42, $143-156$.

Schlegel, R. L., Neu, R. L., Carneiro Leao, J., Reiss, J. A., Nolan, T. B., \& Gardner, L. I. (1967). Cri-du-chat syndrome in a 10 year old girl with deletion of the short arms of chromosome number 5. Helvetica Paediatrica Acta, 22, 2-12.

Shriberg, L. D., \& Kwiatkowski, J. (1982). Phonological disorders 1: A diagnostic classification-system. Journal of Speech and Hearing Disorders, 47, 226-241.

Shriberg, L. D., Austin, D., Lewis, B. A., McSweeny, J. L., \& Wilson, D. L. (1997). The percentage of consonants correct (PCC) metric: Extensions and reliability data. Journal of Speech, Language, and Hearing Research, 40, 708-722.

Small, Larry H.. (2005). Fundamentals of phonetics: A practical guide for students (2nd ed.). Boston: Allyn and Bacon.

Smit, A. B. (1993). Phonologic error distributions in the Iowa-Nebraska articulation norms project: Word-initial consonant clusters. Journal of Speech and Hearing Research, 36, 931-947.

Sohner, L., \& Mitchell, P. (1991). Phonatory and phonetic characteristics of prelinguistic vocal development in cri du chat syndrome. Journal of Communication Disorders, 24, 13-20.

Sparks, S., \& Hutchinson, B. (1980). Cri du chat: Report of a case. Journal of Communication Disorders, 13, 9-13.

Stoel-Gammon, C. (1991). Theories of phonological development and their implications for phonological disorders. In M. Yava (Ed.), Phonological disorders in children (pp. 16-36). London, Routledge: Theory, Research, and Practice.

Studdert-Kennedy, M., \& Goldstein, L. (2003). Launching language: Gestural origin of discrete infinity. In M. Christiansen \& S. Kirby (Eds.), Language evolution: The states of the art (pp. 235-254). Oxford: Oxford University Press.

Studdert-Kennedy, M., \& Goodell, E. W. (1995). Gestures, features and segments in early child speech. In B. de Gelder \& J. Morais (Eds.), Speech and reading. A comparative approach (pp. 65-88). UK/Hove: Erlbaum/ Taylor and Francis.

Vihman, M. M. (1996). Phonological development: The origins of language in the child. Oxford: Blackwell.

Wilkins, L. E., Brown, J. A., \& Wolf, B. (1980). Psychomotor development in 65 home-reared children with cridu-chat syndrome. The Journal of Pediatrics, 97, 401-405.

Wu, Q., Niebuhr, E., Yang, H., \& Hansen, L. (2005). Determination of the 'critical region' for cat-like cry of Cridu-chat syndrome an analysis of candidate genes by quantitative PCR. European Journal of Human Genetics, $13,475-485$. 